\title{
Tear osmolarity and dry eye symptoms in diabetics
}

This article was published in the following Dove Press journal:

Clinical Ophthalmology

10 March 2014

Number of times this article has been viewed

\author{
Nicole Fuerst ${ }^{1}$ \\ Nicole Langelier' \\ Mina Massaro-Giordano' \\ Maxwell Pistilli' \\ Kalliopi Stasi ${ }^{1}$ \\ Carrie Burns ${ }^{2}$ \\ Serena Cardillo \\ Vatinee $Y$ Bunya' \\ 'Department of Ophthalmology, \\ Perelman School of Medicine, \\ University of Pennsylvania, \\ Philadelphia, PA, USA; ${ }^{2}$ Division \\ of Endocrinology, Diabetes, and \\ Metabolism, Perelman School of \\ Medicine, University of Pennsylvania, \\ Philadelphia, PA, USA
}

Purpose: To assess the relationship between tear osmolarity and dry eye symptoms in patients with diabetes.

Patients and methods: Fifty patients with diabetes were enrolled. Demographic information and past medical history were recorded. Symptoms were assessed using the ocular surface disease index (OSDI). Tear osmolarity of each eye was measured with the TearLab ${ }^{\circledR}$ Osmolarity System.

Results: The majority of the subjects were female (76\%), African American (56\%), and/or had a diagnosis of type 2 diabetes ( $82 \%$ ). The mean \pm standard deviation (SD) for age was $54.6 \pm 13.4$, and maximum tear osmolarity was $304.6 \pm 12.7 \mathrm{mOsm} / \mathrm{L}$. Men had higher osmolarity than women (mean \pm standard error (SE) $311.8 \pm 4.0 \mathrm{mOsm} / \mathrm{L}$ versus $302.3 \pm 1.9 \mathrm{mOsm} / \mathrm{L}, P=0.02$ ). Age, race, use of artificial tears, years of diabetes, and hemoglobin A1c did not have a statistically significant association with tear osmolarity. Longer duration of diabetes was associated with lower (less severe) OSDI scores $(r=-0.35, P=0.01)$. Higher tear osmolarity was associated with lower (less severe) OSDI scores $(r=-0.29, P=0.04)$.

Conclusion: Approximately half of the diabetic subjects in our study had elevated tear osmolarity, and half of our population also reported symptoms consistent with dry eye disease. However, the two were slightly inversely related in that those with higher osmolarity reported fewer symptoms. Subjects with a longer duration of diabetes also reported fewer dry eye symptoms. Therefore, health care providers should be aware that patients who are most likely to have ocular surface disease, including those with long-standing diabetes, may not experience symptoms and seek care in a timely manner.

Keywords: dry eye, osmolarity, diabetes

\section{Introduction}

In 2007, the Dry Eye Workshop (DEWS) defined dry eye as "a multifactorial disease of the tears and ocular surface that results in symptoms of discomfort, visual disturbance, and tear film instability. It is accompanied by increased osmolarity of the tear film and inflammation of the ocular surface." Dry eye disease (DED) is common and significantly affects quality of life. The estimated prevalence of DED for women and men over the age of 50 years in the United States is 3.2 million and 1.6 million, respectively. ${ }^{2,3}$ Compared with age-matched controls, patients with dry eye are two to four times more likely to experience difficulty with reading, carrying out professional work, using a computer, watching television, and driving. ${ }^{4}$

The assessment of tear film osmolarity may be helpful in the study of DED, as tear osmolarity changes have been shown to reflect disturbances of the tear film. ${ }^{5-10}$ A recent study using electrical impedance to measure tear osmolarity found that dry eye disease
Penn Dry Eye and Ocular Surface Center,

Scheie Eye Institute, 5I North 39th

Street, Philadelphia, PA 19104, USA

$\mathrm{Tel}+\mathrm{I} 215662979 \mid$

Fax +I 2152434695

Email vatinee.bunya@uphs.upenn.edu 
could be diagnosed with a sensitivity of $87 \%$ and a specificity of $81 \%$ when $316 \mathrm{mOsm} / \mathrm{L}$ was used as a cutoff. ${ }^{9}$ In another study, tear osmolarity had superior diagnostic performance over other dry eye tests, including tear break up time, corneal staining, conjunctival staining, Schirmer's test, and meibomian gland grading. In that study, a tear osmolarity cutoff of $312 \mathrm{mOsm} / \mathrm{L}$ yielded a sensitivity of $73 \%$ and a specificity of $92 \%$ for diagnosing dry eye. ${ }^{10}$

Many systemic diseases such as diabetes can lead to DED through a variety of mechanisms. ${ }^{11-14}$ Although the association between diabetes and dry eye is complex, ${ }^{15}$ most studies support that diabetics experience high rates of DED. ${ }^{15-20}$ In one study, $53 \%$ of subjects with either diabetes or borderline diabetes had self-reported, clinically significant dry eyes. ${ }^{15}$ When severe, dry eye can cause ocular surface abnormalities such as superficial punctate erosions, epithelial defects, and corneal ulcers, which can lead to permanent corneal scarring. It is important to diagnose and treat dry eye in patients with diabetes, because they are already at risk for developing corneal problems. One study reported that $47 \%-64 \%$ of diabetic patients have primary corneal lesions during their lifetime. ${ }^{21}$

As tear osmolarity has been proposed as an objective test to diagnose and follow DED, ${ }^{1}$ we sought to examine whether this would be a useful test in diabetic subjects, with the hope that an early diagnosis of DED could help prevent complications and improve quality of life. Despite numerous studies describing an association between diabetes and DED, to our knowledge, there are few publications describing tear osmolarity as a marker of dry eye severity in diabetes. ${ }^{22-24}$ Additionally, we sought to examine how self-reported dry eye severity related to tear osmolarity in this population. We hypothesized that diabetic subjects would have increased dry eye symptoms and signs, including increased tear osmolarity, and that these would correlate with various parameters of diabetic control and complications. To test this hypothesis, we analyzed the relationship between tear osmolarity and dry eye symptoms in patients with type 1 , type 2 , and steroidinduced diabetes.

\section{Materials and methods}

Subjects were recruited from ophthalmology and endocrinology practices at an academic medical center during the summers of 2010 and 2012. Inclusion criteria were age over 18 years and a diagnosis of diabetes. Exclusion criteria were similar to previous studies of dry eye and tear osmolarity and included history of any significant ocular surface disease or ocular inflammation (other than keratoconjunctivitis sicca), history of ocular surgery within the past year, contact lens wear during the previous month, and the use of eye medications or artificial tears within 2 hours of checking tear osmolarity. ${ }^{25,26}$ Past medical history, including medications, medical conditions, ocular history, years of diabetes, use of insulin, and a hemoglobin A1c (HbA1c) value within the last 3 months was obtained. Symptoms of DED were assessed with the ocular surface disease index (OSDI; Allergan, Inc, Irvine, CA, USA). The OSDI consists of 12 questions on symptoms within the past week and yields scores ranging from 0 (least severe) to 100 (most severe). A score of 12 is typically used as a cutoff for normal, 13-22 for mild dry eye, 23-32 for moderate dry eye, and $\geq 33$ for severe dry eye. ${ }^{27,28}$

Tear osmolarity was measured in each eye with the TearLab $^{\circledR}$ Osmolarity System (TearLab Corporation, San Diego, CA, USA). The system was stored in a temperature and humidity controlled environment, and these values were logged prior to each measurement of tear osmolarity. The system was calibrated at the beginning of each study day according to the manufacturer's instructions; the test cards used for each tear osmolarity measurement were from the same lot numbers as the test cards used to calibrate the machine each day. Tear samples were collected atraumatically from the lateral tear meniscus of the right eye and then the left eye using Pen 1 only for all measurements. A tear osmolarity value of $305 \mathrm{mOsm} / \mathrm{L}$ was used as the cutoff for mild dry eye, ${ }^{6}$ and $316 \mathrm{mOsm} / \mathrm{L}$ was used as the cut-off for more severe dry eye disease. ${ }^{29}$

\section{Statistical analysis}

As recommended by the TearLab ${ }^{\circledR}$ manufacturer, statistical analysis was performed using the maximum osmolarity measurement value of the two eyes. Unless specifically stated, the osmolarity in this analysis will refer to the maximum osmolarity measurement of the two eyes. Statistical analysis using the average tear osmolarity of both eyes is presented in the supplementary materials (Table S1, Table S2 and Figure S1). Patient characteristics with continuous measurements were assessed using Spearman rank-order correlation coefficients to examine pairwise relationships with tear osmolarity or OSDI scores. The differences in tear osmolarity or OSDI between different levels of categorical characteristics were compared using one-way analysis of variance (ANOVA). All analysis was performed in Statistical Applications Software version 9.3 (SAS Inc, Cary, NC, USA).

\section{Results \\ Subject characteristics}

Fifty subjects (38 females and 12 males) with a mean ( \pm standard deviation $[\mathrm{SD}]$ ) age of $54.6 \pm 13.4$ years, ranging 
from 19 to 73 years old were recruited (Table 1). The majority of subjects were female (76\%), African American (56\%), and/or had type 2 diabetes $(82 \%)$. Sixty percent of subjects required insulin treatment, $24 \%$ of subjects had a diagnosis of diabetic nephropathy, $18 \%$ of subjects had a diagnosis of diabetic retinopathy, and $38 \%$ of subjects had a diagnosis of peripheral neuropathy. Thirty-six percent of subjects had an HbA1c value below 7.0\% within the previous 3 months, and $20 \%$ of subjects had an $\mathrm{HbA} 1 \mathrm{c} \geq 9.0 \%$. Fifteen (30\%) subjects reported current use of artificial tears, with frequency ranging from once per week to three times per day. None of the patients reported recent use of topical cyclosporine or ophthalmic ointments. Twenty-seven subjects (54\%) had a tear osmolarity $\leq 305 \mathrm{mOsm} / \mathrm{L}$, and ten subjects (20\%) had a tear osmolarity $\geq 316 \mathrm{mOsm} / \mathrm{L}$ (Table 1 ). The mean of the patients' maximum tear osmolarity was $304.6 \pm 12.7 \mathrm{mOsm} / \mathrm{L}$ (Table 1).

Based on OSDI symptom scores, 24 subjects were classified as normal (48\%), eight subjects had mild dry eye (16\%), nine subjects had moderate dry eye (18\%) and nine subjects had severe dry eye (18\%; Table 1$)$.

\section{Associations with tear osmolarity and dry eye symptoms (OSDI)}

On average, men had higher osmolarity than women (mean, $311.8 \mathrm{mOsm} / \mathrm{L}$ [95\% confidence interval $\{\mathrm{CI}\} 305.1,318.5]$ versus [vs] $302.3 \mathrm{mOsm} / \mathrm{L}$ [298.5, 306.1], $P=0.02$ ) (Table 2). Among our study population, age, race, use of artificial tears, duration of diabetes, years of insulin use, and $\mathrm{HbA} 1 \mathrm{c}$ were not significantly associated with tear osmolarity (Tables 2 and 3).

There was no significant effect of age, race, sex, years of insulin use, or HbA1c value on OSDI symptom scores in our study population (Tables 2 and 3). Longer duration of diabetes was associated with lower OSDI scores ( $r=-0.35$, $P=0.01$ ) (Table 3).

Subjects with higher tear osmolarity had significantly lower OSDI values ( $r=-0.29, P=0.04)$ (Figure 1 and Table 3 ) with 13 of $24(54 \%)$ nonsymptomatic (OSDI $<13)$ patients having high osmolarity $(>305)$, compared with ten of $26(38 \%)$ symptomatic patients (OSDI $\geq 13$ ). Subjects using artificial tears had worse OSDI scores than those not using artificial tears; however, this finding was not statistically significant (25.6 [16.7, 34.4] vs $16.7[10.9,22.5], P=0.11$ ) (Table 2).

\section{Discussion}

\section{Tear osmolarity and diabetes}

Our population of diabetic subjects had an average maximum tear osmolarity of $304.6 \pm 12.7 \mathrm{mOsm} / \mathrm{L}$ with $46 \%$ having a tear
Table I Baseline characteristics of subjects

\begin{tabular}{|c|c|}
\hline Characteristic & $\mathbf{N}(\%)$ \\
\hline \multicolumn{2}{|l|}{ Demographic } \\
\hline \multicolumn{2}{|l|}{ Age } \\
\hline Mean \pm SD & $54.6 \pm 13.4$ \\
\hline \multicolumn{2}{|l|}{ Sex } \\
\hline Female & $38(76 \%)$ \\
\hline Male & $12(24 \%)$ \\
\hline \multicolumn{2}{|l|}{ Race } \\
\hline White & 17 (34\%) \\
\hline African American & $28(56 \%)$ \\
\hline Other & $5(10 \%)$ \\
\hline \multicolumn{2}{|l|}{ Dry eye } \\
\hline \multicolumn{2}{|l|}{ OSDI } \\
\hline Normal $(0-12)$ & $24(48 \%)$ \\
\hline Mild (I3-22) & $8(16 \%)$ \\
\hline Moderate (23-32) & $9(18 \%)$ \\
\hline Severe $(33-100)$ & $9(18 \%)$ \\
\hline Mean \pm SD & $19.3 \pm 18.2$ \\
\hline \multicolumn{2}{|c|}{ Maximum tear osmolarity (mOsm/L) } \\
\hline Normal $(\leq 305)$ & $27(54 \%)$ \\
\hline Mild DED $(>305-<316)$ & $13(26 \%)$ \\
\hline Severe DED $(\geq 316)$ & $10(20 \%)$ \\
\hline Mean \pm SD & $304.6 \pm 12.7$ \\
\hline \multicolumn{2}{|l|}{ Average tear osmolarity } \\
\hline Normal $(\leq 305)$ & $35(70 \%)$ \\
\hline Mild DED $(>305-<316)$ & $14(28 \%)$ \\
\hline Severe DED $(\geq 3 \mid 6)$ & I (2\%) \\
\hline Mean \pm SD & $300.2 \pm 10.1$ \\
\hline \multicolumn{2}{|l|}{ Artificial tears } \\
\hline No & 35 (70\%) \\
\hline Yes & $15(30 \%)$ \\
\hline \multicolumn{2}{|l|}{ Diabetes severity } \\
\hline \multicolumn{2}{|l|}{ Diabetes type } \\
\hline Type I & $4(8 \%)$ \\
\hline Type 2 & $4 \mid(82 \%)$ \\
\hline Steroid-induced & $5(10 \%)$ \\
\hline \multicolumn{2}{|l|}{ Years of diabetes } \\
\hline$<5$ years & $16(32 \%)$ \\
\hline 5 to 10 years & $12(24 \%)$ \\
\hline$>10$ to 20 years & 14 (28\%) \\
\hline$>20$ years & $8(16 \%)$ \\
\hline Mean \pm SD & $11.4 \pm 9.0$ \\
\hline \multicolumn{2}{|l|}{ Insulin } \\
\hline No & $20(40 \%)$ \\
\hline Yes & $30(60 \%)$ \\
\hline \multicolumn{2}{|l|}{ Years of insulin } \\
\hline Never & 20 (40\%) \\
\hline$\leq 5$ years & 20 (40\%) \\
\hline$>5$ years & $10(20 \%)$ \\
\hline Mean \pm SD & $4.5 \pm 7.1$ \\
\hline \multicolumn{2}{|l|}{ Hemoglobin Alc } \\
\hline$<7 \%$ & $18(36 \%)$ \\
\hline $7 \%-<9 \%$ & 17 (34\%) \\
\hline$\geq 9 \%$ & $10(20 \%)$ \\
\hline Unknown & $5(10 \%)$ \\
\hline
\end{tabular}


Table I (Continued)

\begin{tabular}{ll}
\hline Characteristic & N (\%) \\
\hline Mean \pm SD & $7.9 \pm 1.9$ \\
Peripheral neuropathy & \\
No & $27(54 \%)$ \\
Yes & $19(38 \%)$ \\
Unknown & $4(8 \%)$ \\
\hline
\end{tabular}

Abbreviations: N, number; SD, standard deviation; DED, dry eye disease; OSDI, ocular surface disease index.

osmolarity $>305 \mathrm{mOsm} / \mathrm{L}$, which is consistent with mild dry eye using the cutoffs described by Versura et al. ${ }^{6}$ Our findings are similar to the findings of Najafi et al, ${ }^{24}$ who found that in 243 subjects with type 2 diabetes, the mean tear osmolarity using the TearLab ${ }^{\circledR}$ system was $302 \pm 14 \mathrm{mOsm} / \mathrm{L}$. The slightly lower average tear osmolarity found in their study is not unexpected, as they reported the mean of the average tear osmolarity of both eyes instead of the average maximum tear osmolarity.

However, tear osmolarity in our diabetic population was lower than that found by Sağdik et al, ${ }^{22}$ who found an average tear osmolarity of $320 \pm 22 \mathrm{mOsm} / \mathrm{L}$ in diabetic subjects and $308 \pm 18 \mathrm{mOsm} / \mathrm{L}$ in controls. Glycemic control was similar in our study and that of Sağdik et al, with a mean $\mathrm{HbAlc}$ of $7.9 \%$ in both studies. One possible explanation for the difference in tear osmolarity is that Sağdik et al required an eye drop washout period of 12 hours and ointment washout of 5 days, whereas our study required that subjects not use any eye drops for a period of 2 hours as recommended by TearLab and as employed by other tear osmolarity studies..$^{25,26,30}$ Because $30 \%$ of our subjects reported using artificial tears, future studies in our population with a longer washout period may find a maximum tear osmolarity closer to the value found by Sağdik et al. ${ }^{22}$

We also studied whether or not markers of diabetic severity correlated with tear osmolarity. We did not find a significant relationship between tear osmolarity and the duration of diabetes, HbA1c level, or use of insulin. This is similar to the findings of Aragona et al, ${ }^{23}$ who found that tear osmolarity in patients with type 1 diabetes was not correlated with $\mathrm{HbA1c}$, diabetes duration, or retinopathy. Similarly, Sağdik et a ${ }^{22}$ did not find a correlation between tear osmolarity and $\mathrm{HbA} 1 \mathrm{c}$; however, their study did find that tear osmolarity increased with duration of diabetes. ${ }^{22}$

\section{Relationship of dry eye symptoms with diabetic severity markers}

Based on OSDI symptom scores, $52 \%$ of our diabetic population had at least mild dry eye, and subjects with a

Table 2 Differences in categorical variables by either tear osmolarity or OSDI using maximum tear osmolarity for analysis

\begin{tabular}{|c|c|c|c|c|}
\hline \multirow[t]{2}{*}{ Baseline characteristics } & \multicolumn{2}{|c|}{ Maximum tear osmolarity (mOsm/L) } & \multicolumn{2}{|l|}{ OSDI } \\
\hline & Mean $(95 \% \mathrm{Cl} *)$ & $P$-value** & Mean $(95 \% \mathrm{Cl} *)$ & $P$-value** \\
\hline \multicolumn{5}{|l|}{ Demographics } \\
\hline \multicolumn{5}{|l|}{ Sex } \\
\hline Female & $302.3(298.5,306.1)$ & 0.02 & $21.0(15.4,26.7)$ & 0.24 \\
\hline Male & $3 \mid I .8(305.1,318.5)$ & & I4.I (4.0, 24.I) & \\
\hline \multicolumn{5}{|l|}{ Race } \\
\hline White & $303.4(297.5,309.3)$ & 0.64 & I8.2 $(9.8,26.6)$ & 0.49 \\
\hline African American & $304.5(299.9,309.1)$ & & $21.4(14.9,28.0)$ & \\
\hline Other & $309.4(298.5,320.3)$ & & II.5 $(0,27.0)$ & \\
\hline \multicolumn{5}{|l|}{ Dry eye } \\
\hline \multicolumn{5}{|l|}{ Artificial tears } \\
\hline No & $305.6(301.4,309.7)$ & 0.40 & $16.7(10.9,22.5)$ & 0.11 \\
\hline Yes & $302.3(296.0,308.6)$ & & $25.6(16.7,34.4)$ & \\
\hline \multicolumn{5}{|l|}{ Diabetes severity } \\
\hline \multicolumn{5}{|l|}{ Diabetes type } \\
\hline Type I & $305.5(293.3,317.7)$ & 0.62 & $4.0(0,20.4)$ & 0.03 \\
\hline Type 2 & $305.1(301.3,309.0)$ & & $19.0(13.8,24.1)$ & \\
\hline Steroid-induced & $299.4(288.5,3 \mid 0.3)$ & & $34.8(20.1,49.5)$ & \\
\hline \multicolumn{5}{|l|}{ Insulin } \\
\hline No & $304.5(299.0,309.9)$ & 0.94 & $16.7(8.9,24.5)$ & 0.39 \\
\hline Yes & $304.7(300.2,309.2)$ & & $21.1(14.7,27.5)$ & \\
\hline \multicolumn{5}{|l|}{ Peripheral neuropathy } \\
\hline No & $301.9(297.4,306.4)$ & 0.10 & $18.2(11.5,25.0)$ & 0.68 \\
\hline Yes & $306.2(300.8,3 \mid I .5)$ & & $21.9(13.9,29.9)$ & \\
\hline Unknown & $315.3(303.5,327.0)$ & & $14.7(0,32.2)$ & \\
\hline
\end{tabular}

Notes: $* 95 \%$ confidence interval (Cl). Negative values for OSDI have been changed to zero; **analysis of variance (ANOVA).

Abbreviation: OSDI, ocular surface disease index. 
Table 3 Correlations between continuous variables and either tear osmolarity or OSDI using maximum tear osmolarity for analysis

\begin{tabular}{|c|c|c|c|c|}
\hline \multirow[t]{2}{*}{ Characteristic } & \multicolumn{2}{|c|}{$\begin{array}{l}\text { Maximum tear } \\
\text { osmolarity }\end{array}$} & \multicolumn{2}{|l|}{ OSDI } \\
\hline & rho* & $P$-value & rho* & $P$-value \\
\hline Age & $\begin{array}{l}-0.12 \\
(-0.39,0.16)\end{array}$ & 0.39 & $\begin{array}{l}-0.04 \\
(-0.31,0.25)\end{array}$ & $0.8 \mathrm{I}$ \\
\hline OSDI & $\begin{array}{l}-0.29 \\
(-0.53,-0.02)\end{array}$ & 0.04 & $\mathrm{n} / \mathrm{a}$ & \\
\hline $\begin{array}{l}\text { Maximum tear } \\
\text { osmolarity }\end{array}$ & $\mathrm{n} / \mathrm{a}$ & & $\begin{array}{l}-0.29 \\
(-0.53,-0.02)\end{array}$ & 0.04 \\
\hline Years of diabetes & $\begin{array}{l}0.06 \\
(-0.22,0.34)\end{array}$ & 0.67 & $\begin{array}{l}-0.35 \\
(-0.57,-0.08)\end{array}$ & 0.01 \\
\hline Years of insulin & $\begin{array}{l}0.07 \\
(-0.21,0.35)\end{array}$ & 0.61 & $\begin{array}{l}-0.13 \\
(-0.40,0.15)\end{array}$ & 0.36 \\
\hline Hemoglobin Alc & $\begin{array}{l}-0.02 \\
(-0.31,0.28)\end{array}$ & 0.91 & $\begin{array}{l}0.07 \\
(-0.23,0.36)\end{array}$ & 0.64 \\
\hline
\end{tabular}

Note: *Spearman correlation coefficient with $95 \%$ confidence interval limits. Abbreviations: OSDI, ocular surface disease index; n/a, not applicable.

shorter duration of diabetes reported the greatest symptoms, whereas patients with longstanding diabetes reported fewer symptoms. The frequency of dry eye symptoms in our study is similar to that of Manaviat et al, ${ }^{31}$ who found that $54 \%$ of 199 diabetic subjects had dry eye symptoms. In contrast to our study, Manaviat et al found a significant positive association between dry eye syndrome and the duration of diabetes. However, our finding that patients with longstand-

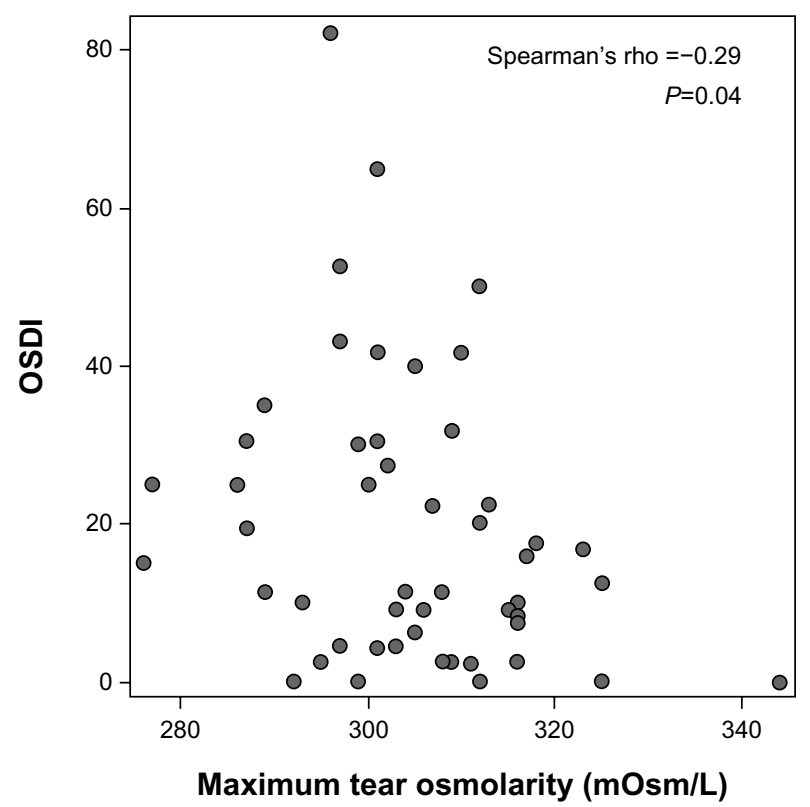

Figure I Maximum tear osmolarity versus OSDI.

Note: There was a statistically significant negative correlation between OSDI and tear osmolarity $(r=-0.29, P=0.04)$ when the data were analyzed using the maximum tear osmolarity from the two eyes.

Abbreviation: OSDI, ocular surface disease index. ing diabetes had fewer DED symptoms is in agreement with previous evidence showing that, over time, poorly controlled diabetes can result in reduced corneal sensation, ${ }^{32-36}$ and therefore, reduced dry eye symptoms. Moreover, in vivo confocal microscopy has shown that diabetic patients have reduced corneal nerve fiber length, thickness, and branching compared with non-diabetic controls. ${ }^{37-39}$ Similarly, patients with severe diabetic neurotrophic keratopathy exhibit signs of severe dryness with very few symptoms. ${ }^{11}$

We did not find a relationship between DED symptoms and $\mathrm{HbA1c}$ in our study. This is in contrast to the results of previous research, ${ }^{17,19,24,31}$ including the results of Kaiserman et al, ${ }^{17}$ who found a greater use of artificial tears among diabetic subjects with a higher $\mathrm{HbA} 1 \mathrm{c}$. It is possible that $\mathrm{HbA1c}$ levels did not correlate with dry eye symptoms in our study because $\mathrm{HbA} 1 \mathrm{c}$ reflects only the average blood glucose level over the previous 3 months. Therefore, HbA1c levels may not necessarily correlate with decreased corneal sensation, which can affect the perception of dry eye symptoms and likely takes years of poorly controlled diabetes to develop.

\section{Tear osmolarity and dry eye symptoms in diabetic patients}

In our diabetic population, subjects with higher tear osmolarity reported fewer dry eye symptoms. This association is the opposite of that found in a previous study showing a significant small positive correlation between tear osmolarity and OSDI score among the general population and an even stronger correlation among moderate dry eye subjects. ${ }^{6}$ One possible explanation for the negative correlation seen in our study is that, as mentioned previously, diabetic subjects may have reduced corneal sensitivity, ${ }^{34,35}$ which could lead to decreased awareness of dry eye symptoms. Reduced corneal sensation can also lead to a reduced blink rate and increased tear evaporation. ${ }^{14}$ In addition, diabetic patients also show reduced tear production, with some studies showing a reduction in basal tear production ${ }^{32,35}$ and others showing a reduction in reflex tearing only. ${ }^{33}$ Both increased tear evaporation and reduced tear production can result in increased tear osmolarity. ${ }^{40}$ Therefore, it is possible that diabetic patients with a higher tear osmolarity resulting from increased tear evaporation and reduced tear production may also report a lower OSDI score because of their decreased corneal sensation.

\section{Limitations}

Our study did not have sufficient power to determine whether there is a relationship between type of diabetes (type 1, type 2, 
steroid-induced), diabetic microvascular complications (retinopathy, neuropathy, or nephropathy) and tear osmolarity or DED symptoms. Future studies enrolling a larger number of diabetic subjects that also include analysis of corneal sensitivity and other markers of DED will be helpful in diagnosis and treatment of dry eye disease in this population.

\section{Conclusion}

Approximately half of our diabetic subjects had a tear osmolarity consistent with dry eye disease and 52\% reported DED symptoms consistent with at least mild dry eye disease, but we found that subjects with higher tear osmolarity reported fewer dry eye symptoms. We also found that subjects with a longer duration of diabetes reported fewer dry eye symptoms. Therefore, health care providers should be aware that patients with long-standing diabetes may not experience symptoms and seek care. It is important that diabetics receive regular eye exams not only to check for signs of diabetic retinopathy, but also to evaluate patients for occult dry eye disease which could be affecting their vision.

\section{Acknowledgment}

Nicole Fuerst and Nicole Langelier contributed equally to this work.

\section{Disclosure}

Mina Massaro-Giordano receives funding support from Research to Prevent Blindness. Vatinee Y Bunya has received research supplies from TearLab ${ }^{\circledR}$ for a separate study and receives support from the National Eye Institute (K12-EY-015398) and Research to Prevent Blindness. Maxwell Pistilli receives support from a grant from the National Eye Institute (P30 EY001583). The remaining authors have no conflicts of interest to report.

\section{References}

1. The definition and classification of dry eye disease: Report of the definition and classification subcommittee of the International Dry Eye WorkShop (2007). The Ocular Surface. 2007;5(2):75-92.

2. Schaumberg DA, Sullivan DA, Buring JE, Dana MR. Prevalence of dry eye syndrome among US women. Am J Ophthalmol. 2003;136(2): 318-326.

3. Schaumberg DA, Dana R, Buring JE, Sullivan DA. Prevalence of dry eye disease among US men: estimates from the physicians' health studies. Arch Ophthalmol. 2009;127(6):763-768.

4. Miljanović B, Dana R, Sullivan DA, Schaumberg DA. Impact of dry eye syndrome on vision-related quality of life. Am J Ophthalmol. 2007;143(3):409-415.

5. Liu H, Begley C, Chen M, et al. A link between tear instability and hyperosmolarity in dry eye. Invest Ophthalmol Vis Sci. 2009;50(8): 3671-3679.
6. Versura P, Profazio V, Campos EC. Performance of tear osmolarity compared to previous diagnostic tests for dry eye diseases. Curr Eye Res. 2010;35(7):553-564.

7. Keech A, Senchyna M, Jones L. Impact of time between collection and collection method on human tear fluid osmolarity. Curr Eye Res. 2013;38(4):428-436.

8. Tomlinson A, Khanal S, Ramaesh K, Diaper C, McFadyen A. Tear film osmolarity: determination of a referent for dry eye diagnosis. Invest Ophthalmol Vis Sci. 2006;47(10):4309-4315.

9. Jacobi C, Jacobi A, Kruse FE, Cursiefen C. Tear film osmolarity measurements in dry eye disease using electrical impedance technology. Cornea. 2011;30(12):1289-1292.

10. Lemp MA, Bron AJ, Baudouin C, et al. Tear osmolarity in the diagnosis and management of dry eye disease. Am J Ophthalmol. 2011;151(5): 792-798. e1.

11. Alves Mde C, Carvalheira JB, Módulo CM, Rocha EM. Tear film and ocular surface changes in diabetes mellitus. Arqs Bras Oftalmol. 2008;71(6):96-103.

12. Goebbels M. Tear secretion and tear film function in insulin dependent diabetics. Br J Ophthalmol. 2000;84(1):19-21.

13. Figueroa-OrtizLC, Jiménez RodriguezE, Garcia-Ben A, Garcia-Campos J. [Study of tear function and the conjunctival surface in diabetic patients]. Arch Soc Esp Oftalmol. 2011;86(4):107-112. Spanish.

14. Inoue $\mathrm{K}$, Okugawa $\mathrm{K}$, Amano $\mathrm{S}$, et al. Blinking and superficial punctate keratopathy in patients with diabetes mellitus. Eye (Lond). 2005;19(4): 418-421.

15. Hom M, De Land P. Self-reported dry eyes and diabetic history. Optometry. 2006;77(11):554-558.

16. Chiang PP, Lamoureux EL, Zheng Y, et al. Frequency and risk factors of non-retinopathy ocular conditions in people with diabetes: the Singapore Malay Eye Study. Diabet Med. 2013;30(2): e32-e40.

17. Kaiserman I, Kaiserman N, Nakar S, Vinker S. Dry eye in diabetic patients. Am J Ophthalmol. 2005;139(3):498-503.

18. Seifart U, Strempel I. [The dry eye and diabetes mellitus]. Ophthalmologe. 1994;91(2):235-239. German.

19. Nepp J, Abela C, Polzer I, Derbolav A, Wedrich A. Is there a correlation between the severity of diabetic retinopathy and keratoconjunctivitis sicca? Cornea. 2000;19(4):487-491.

20. Ozdemir M, Buyukbese MA, Cetinkaya A, Ozdemir G. Risk factors for ocular surface disorders in patients with diabetes mellitus. Diabetes Res Clin Pract. 2003;59(3):195-199.

21. Schultz RO, Van Horn DL, Peters MA, Klewin KM, Schutten WH. Diabetic keratopathy. Trans Am Ophthalmol Soc. 1981;79:180-199.

22. Sağdik HM, Tetikoğlu M, Uçar F, Uğurbaş SC, Uğurbaş SH. Tear film osmolarity in patients with diabetes mellitus. Ophthalmic Res. 2013;50(1):1-5.

23. Aragona P, Giuffrida S, Di Stefano G, et al. Ocular surface changes in type 1 diabetic patients. Adv Exp Med Biol. 2002;506(Pt A): 667-672.

24. Najafi L, Malek M, Valojerdi AE, et al. Dry eye and its correlation to diabetes microvascular complications in people with type 2 diabetes mellitus. J Diabetes Complications. 2013;27(5):459-462.

25. Sullivan BD, Whitmer D, Nichols KK, et al. An objective approach to dry eye disease severity. Invest Ophthalmol Vis Sci. 2010;51(12): 6125-6130.

26. Sullivan BD, Crews LA, Sonmez B, et al. Clinical utility of objective tests for dry eye disease: Variability over time and implications for clinical trials and disease management. Cornea. 2012;31(9):1000-1008.

27. Miller KL, Walt JG, Mink DR, et al. Minimal clinically important difference for the ocular surface disease index. Arch Ophthalmol. 2010;128(1):94-101.

28. Schiffman RM, Christianson MD, Jacobsen G, Hirsch JD, Reis BL. Reliability and validity of the ocular surface disease index. Arch Ophthalmol. 2000;118(5):615-621. 
29. Tomlinson A, McCann LC, Pearce EI. Comparison of human tear film osmolarity measured by electrical impedance and freezing point depression techniques. Cornea. 2010;29(9):1036-1041.

30. Tearlab.com [homepage on the internet]. TearLab ${ }^{\mathrm{TM}}$ research guide tips and recommendations. 930082 rev. B TearLab research guide. Available from: http://www.tearlab.com/products/doctors/research.htm. Accessed October 19, 2013.

31. Manaviat MR, Rashidi M, Afkhami-Ardekani M, Shoja MR. Prevalence of dry eye syndrome and diabetic retinopathy in type 2 diabetic patients. BMC Ophthalmol. 2008;8:10.

32. Dogru M, Katakami C, Inoue M. Tear function and ocular surface changes in noninsulin-dependent diabetes mellitus. Ophthalmology. 2001;108(3):586-592.

33. Saito J, Enoki M, Hara M, Morishige N, Chikama T, Nishida T. Correlation of corneal sensation, but not of basal or reflex tear secretion, with the stage of diabetic retinopathy. Cornea. 2003;22(1):15-18.

34. Nielsen NV. Corneal sensitivity and vibratory perception in diabetes mellitus. Acta Ophthalmol (Copenh). 1978;56(3):406-411.
35. Cousen P, Cackett P, Bennett H, Swa K, Dhillon B. Tear production and corneal sensitivity in diabetes. J Diabetes Complications. 2007;21(6): 371-373.

36. Yoon KC, Im SK, Seo MS. Changes of tear film and ocular surface in diabetes mellitus. Korean J Ophthalmol. 2004;18(2):168-174.

37. Nitoda E, Kallinikos P, Pallikaris A, et al. Correlation of diabetic retinopathy and corneal neuropathy using confocal microscopy. Curr Eye Res. 2012;37(10):898-906.

38. Midena E, Brugin E, Ghirlando A, Sommavilla M, Avogaro A. Corneal diabetic neuropathy: A confocal microscopy study. J Refract Surg. 2006;22(9):S1047-S1052.

39. Messmer EM, Schmid-Tannwald C, Zapp D, Kampik A. In vivo confocal microscopy of corneal small fiber damage in diabetes mellitus. Graefes Arch Clin Exp Ophthalmol. 2010;248(9):1307-1312.

40. Gilbard JP. Dry eye, blepharitis and chronic eye irritation: divide and conquer. J Ophthalmic Nurs Technol. 1999;18(3):109-115. 


\section{Supplementary materials}

Table SI Differences in categorical variables by either tear osmolarity or OSDI

\begin{tabular}{|c|c|c|c|c|}
\hline \multirow[t]{2}{*}{ Baseline characteristics } & \multicolumn{2}{|c|}{ Average tear osmolarity (mOsm/L) } & \multicolumn{2}{|l|}{ OSDI } \\
\hline & Mean $(95 \% \mathrm{Cl} *)$ & $P$-value** & Mean $\left(95 \% \mathrm{Cl}^{*}\right)$ & $P$-value*** \\
\hline \multicolumn{5}{|l|}{ Demographics } \\
\hline \multicolumn{5}{|l|}{ Sex } \\
\hline Female & $298.3(295.3,301.3)$ & 0.01 & $21.0(15.4,26.7)$ & 0.24 \\
\hline Male & $306.2(300.8,3 \mid 1.5)$ & & I4.I $(4.0,24.1)$ & \\
\hline \multicolumn{5}{|l|}{ Race } \\
\hline White & $298.6(293.8,303.3)$ & 0.59 & $18.2(9.8,26.6)$ & 0.49 \\
\hline African American & $300.5(296.8,304.2)$ & & $21.4(14.9,28.0)$ & \\
\hline Other & $303.6(294.9,3 \mid 2.3)$ & & II.5 $(0,27.0)$ & \\
\hline \multicolumn{5}{|l|}{ Dry eye } \\
\hline \multicolumn{5}{|l|}{ Artificial tears } \\
\hline No & $300.8(297.5,304.1)$ & 0.51 & $16.7(10.9,22.5)$ & 0.11 \\
\hline Yes & $298.7(293.7,303.8)$ & & $25.6(16.7,34.4)$ & \\
\hline \multicolumn{5}{|l|}{ Diabetes severity } \\
\hline \multicolumn{5}{|l|}{ Diabetes type } \\
\hline Type I & $300.6(290.9,310.3)$ & 0.49 & $4.0(0,20.4)$ & 0.03 \\
\hline Type 2 & $300.7(297.7,303.8)$ & & $19.0(13.8,24.1)$ & \\
\hline Steroid-induced & $295.1(286.4,303.8)$ & & $34.8(20.1,49.5)$ & \\
\hline \multicolumn{5}{|l|}{ Insulin } \\
\hline No & $299.8(295.4,304.2)$ & 0.82 & $16.7(8.9,24.5)$ & 0.39 \\
\hline Yes & $300.4(296.8,304.0)$ & & $21.1(14.7,27.5)$ & \\
\hline \multicolumn{5}{|l|}{ Peripheral neuropathy } \\
\hline No & $297.5(293.9,301.1)$ & 0.06 & I8.2 (II.5, 25.0) & 0.68 \\
\hline Yes & $302.3(298.0,306.5)$ & & $21.9(13.9,29.9)$ & \\
\hline Unknown & $308.3(299.0,317.5)$ & & $14.7(0,32.2)$ & \\
\hline
\end{tabular}

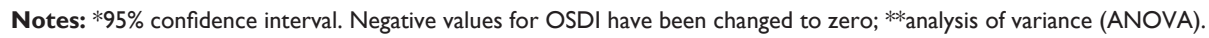

Abbreviations: $\mathrm{Cl}$, confidence interval; OSDI, ocular surface disease index.

Table S2 Correlations between continuous variables and either tear osmolarity or OSDI

\begin{tabular}{|c|c|c|c|c|}
\hline \multirow[t]{2}{*}{ Characteristic } & \multicolumn{2}{|c|}{$\begin{array}{l}\text { Average tear } \\
\text { osmolarity }(\mathrm{mOsm} / \mathrm{L})\end{array}$} & \multicolumn{2}{|l|}{ OSDI } \\
\hline & rho* & $P$-value & rho* & $P$-value \\
\hline Age & $\begin{array}{l}-0.13 \\
(-0.39,0.16)\end{array}$ & 0.38 & $\begin{array}{l}-0.04 \\
(-0.31,0.25)\end{array}$ & 0.81 \\
\hline OSDI & $\begin{array}{l}-0.18 \\
(-0.44,0.10)\end{array}$ & 0.20 & $\mathrm{n} / \mathrm{a}$ & \\
\hline $\begin{array}{l}\text { Average tear } \\
\text { osmolarity }\end{array}$ & $\mathrm{n} / \mathrm{a}$ & & $\begin{array}{l}-0.18 \\
(-0.44,0.10)\end{array}$ & 0.20 \\
\hline $\begin{array}{l}\text { Years of } \\
\text { diabetes }\end{array}$ & $\begin{array}{l}0.07 \\
(-0.21,0.35)\end{array}$ & 0.61 & $\begin{array}{l}-0.35 \\
(-0.57,-0.08)\end{array}$ & 0.01 \\
\hline Years of insulin & $\begin{array}{l}0.06 \\
(-0.22,0.34)\end{array}$ & 0.66 & $\begin{array}{l}-0.13(-0.40 \\
0.15)\end{array}$ & 0.36 \\
\hline Hemoglobin Alc & $\begin{array}{l}0.00 \\
(-0.29,0.30)\end{array}$ & 0.98 & $\begin{array}{l}0.07 \\
(-0.23,0.36)\end{array}$ & 0.64 \\
\hline
\end{tabular}

Note: *Spearman correlation coefficient with $95 \%$ confidence interval limits.

Abbreviations: OSDI, ocular surface disease index; n/a, not applicable. 


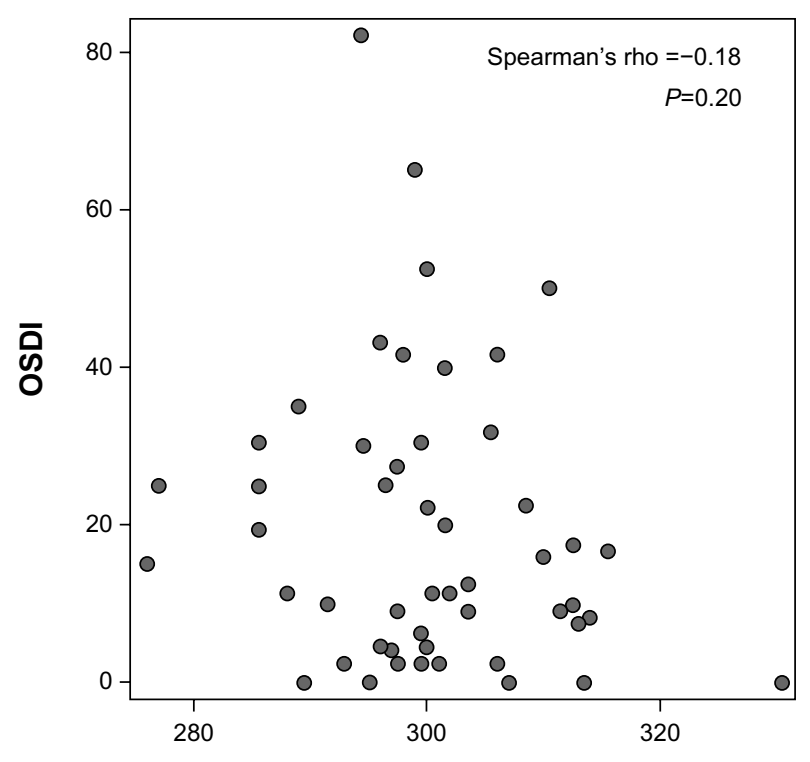

Average tear osmolarity (mOsm/L)

Figure SI Average tear osmolarity versus OSDI.

Note: Subjects with a higher average tear osmolarity trended toward having a lower OSDI value.

Abbreviation: OSDI, ocular surface disease index.

\section{Publish your work in this journal}

Clinical Ophthalmology is an international, peer-reviewed journal covering all subspecialties within ophthalmology. Key topics include: Optometry; Visual science; Pharmacology and drug therapy in eye diseases; Basic Sciences; Primary and Secondary eye care; Patient Safety and Quality of Care Improvements. This journal is indexed on

Submit your manuscript here: http://www.dovepress.com/clinical-ophthalmology-journal
PubMed Central and CAS, and is the official journal of The Society of Clinical Ophthalmology (SCO). The manuscript management system is completely online and includes a very quick and fair peer-review system, which is all easy to use. Visit http://www.dovepress.com/ testimonials.php to read real quotes from published authors. 